\section{RhoC is dispensable for embryogenesis and tumor initiation but essential for metastasis}

\author{
Anne Hakem, ${ }^{1}$ Otto Sanchez-Sweatman, ${ }^{2}$ \\ Annick You-Ten, ${ }^{1}$ Gordon Duncan, ${ }^{1}$ \\ Andrew Wakeham, ${ }^{1}$ Rama Khokha, ${ }^{2}$ and \\ Tak W. Mak ${ }^{1,2,3}$ \\ ${ }^{1}$ Campbell Family Institute for Breast Cancer Research, \\ Toronto, Ontario, M5G 2C1, Canada; ${ }^{2}$ Ontario Cancer \\ Institute, Toronto, Ontario, M5G 2C1, Canada
}

The Rho proteins are Ras-related guanosine triphosphatases (GTPases) that function in cytoskeletal reorganization, cell migration, and stress fiber and focal adhesion formation. Overexpression of RhoC enhances the ability of melanoma cells to exit the blood and colonize the lungs. However, in vivo confirmation of RhoC's role in metastasis has awaited a RhoC-deficient mouse model. Here we report the generation of RhoC-deficient mice and show that RhoC is dispensable for embryonic and post-natal development. We demonstrate that loss of RhoC does not affect tumor development but decreases tumor cell motility and metastatic cell survival leading to a drastic inhibition of metastasis.

Supplemental material is available at http://www.genesdev.org.

Received February 25, 2005; revised version accepted June 24, 2005.

The Ras superfamily of GTP-binding proteins relays extracellular ligand-mediated signals to cytoplasmic signaling pathways (Etienne-Manneville and Hall 2002). The Ras superfamily is subdivided into several subgroups, including the Rho-GTPase (guanosine triphosphatases) family of proteins which are ubiquitously expressed from yeast to humans. The Rho-GTPase family is further subdivided into the RhoA, RhoB, and RhoC, Rac, and CDC42 subfamilies. The mammalian Rho and Rho-related GTPases comprise at least 20 distinct proteins which share $50 \%-55 \%$ homology at the protein level. These enzymes play crucial roles in diverse cellular pathways such as membrane trafficking, transcriptional regulation, cell growth control and development (Schmidt and Hall 2002; Raftopoulou and Hall 2004).

In general, the Rho-GTPases function as molecular switches, cycling between an inactive GDP-bound form and an active GTP-bound state. The activated GTPbound Rho-GTPases then interact with a broad spectrum of diverse effectors to mediate their functions. It has been a major challenge to understand how these inter-

[Keywords: GTPase; RhoC; breast cancer; metastasis] ${ }^{3}$ Corresponding author.

E-MAIL tmak@uhnres.utoronto.ca; FAX (416) 204-5300.

Article published online ahead of print. Article and publication date are at http://www.genesdev.org/cgi/doi/10.1101/gad.1310805. actions with downstream effectors occur and translate into cellular activity. To date, due to the availability of the appropriate reagents, RhoA, Rac1, and Cdc42 have been the most intensively studied members of this group. It has been shown that RhoA acts on at least 11 downstream effectors (Bishop and Hall 2000) which primarily regulate actin cytoskeletal organization. Effects on the cytoskeleton in turn influence cell shape, cell motility, and cell-cell interactions. Another function identified for Rho-GTPases is the regulation of transcription factor expression, particularly c-fos and c-jun. The Rho family is also involved in controlling cell cycle progression through the G1 phase. Several lines of evidence implicate Rho family members in tumorigenesis. The introduction of constitutively active RhoA into a cell results in transformation or increased invasiveness, depending on cell type (Yoshioka et al. 1999). Furthermore, RhoA, RhoB, and Rac are all essential for Ras-mediated transformation in vitro (Weber et al. 1997; Olson et al. 1998). Finally, overexpression of RhoC increases angiogenic factors in breast epithelial cells in vitro (van Golen et al. 2000) and enhances the ability of melanoma cells to exit the blood and colonize the lungs (Clark et al. 2000). In this study, we provide insight into the in vivo functions of RhoC, and demonstrate that this GTPase is crucial for tumor metastasis.

\section{Results and Discussion}

$R h o C^{+/-}$embryonic stem (ES) cells were generated by homologous recombination using a targeting vector in which exons 2 and 3 of the murine RhoC gene were flanked by Loxp sites (Fig. 1A). Deletion of RhoC exons 2 and 3 should introduce termination codons into all three reading frames and remove $70 \%$ of the protein sequence. The targeting construct was electroporated into E14K ES cells and several ES clones (Rhoc flox2-3neo/wt) carrying the floxed $R$ hoC allele were obtained (Fig. 1B). Expression of Cre recombinase in $R h o C^{\text {flox2-3neo/wt }}$ ES yielded several $R h o C^{\Delta 2-3 / w t}$ clones. These clones were used to generate $R h o C^{\Delta 2-3 / w t}\left(R h o C^{+/-}\right)$mice as described in Materials and Methods. $R h o C^{+/-}$mice were then intercrossed to obtain homozygous $R_{h o c}{ }^{\Delta 2-3 / \Delta 2-3}\left(R_{h o C^{-1}}\right)$ mice (Fig. 1C). $R h_{0} C^{-/}$mice were born at the expected Mendelian ratio and were viable and fertile. $R h o C^{-/-}$primary murine embryonic fibroblasts (MEFs) were established from E13.5 wild-type or $R \mathrm{RoC}^{-/-}$mutant embryos. Northern blot analysis of wild-type and $R h o C^{-/}$MEF RNA using a full-length mouse $R$ hoC cDNA probe confirmed the absence of $R$ hoC transcripts in the mutant cells, establishing that $R h o C^{\Delta 2-3 / \Delta 2-3}$ was a null mutation (Fig. 1D).

It is well known that GTPases have important roles in T- and B-cell development (Henning et al. 1997; Corre et al. 2001). To determine the role of RhoC in these processes, we analyzed T- and B-cell lineages in wild-type and $\mathrm{RhoC}^{-/-}$mice of 6-10 wk of age. Total thymocyte numbers were similar in wild-type $(120 \pm 6, n=7)$ and RhoC $^{-/-}(112 \pm 6, n=7)$ animals. There were also no significant differences in total lymph node (LN) (71 \pm 10 , $n=8 ; 85 \pm 8, n=8$ ) or splenic lymphocyte numbers (64 $\pm 10, n=8 ; 70 \pm 5, n=8)$. Flow cytometric analysis failed to reveal any alterations in various subpopulations of thymocytes, splenocytes, or LN cells (Fig. 2A). T- and 
A

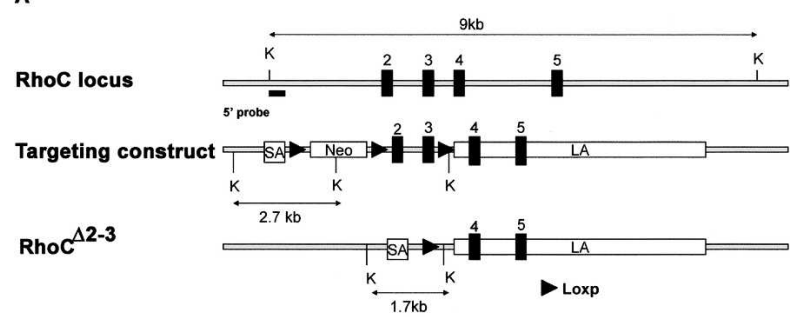

$\mathbf{B}$

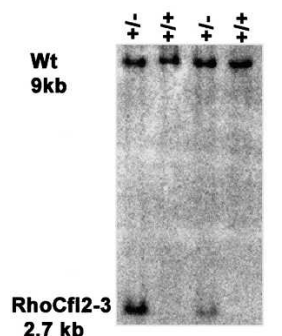

C

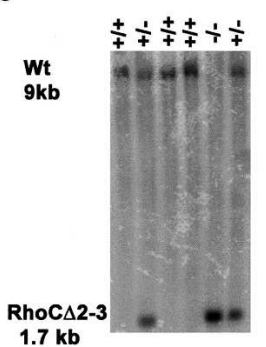

D

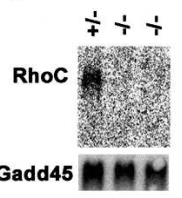

Figure 1. Generation of RhoC-deficient mice. $(A)$ Schematic representations of the wild-type $R$ hoC locus, the targeting construct (floxed 2-3 Neo), and the mutant $R h o C^{\Delta 2-3}$ allele. Exons are indicated by filled boxes and Loxp sites are indicated by triangles. The 5 '-flanking probe used for Southern hybridizations is indicated. $(\mathrm{K})$ $K$ pn 1 site. $(B)$ Identification of ES cell clones bearing the floxed $R h o C$ allele $\left(R h o C^{f 12-3}\right)$. Clones that had undergone homologous recombination at the $R$ hoC locus were first identified by PCR (not shown) and then confirmed by Southern blotting using the $5^{\prime}$ probe indicated in $A$. Four independent ES clones were subsequently transfected with Cre recombinase to generate ES cell clones lacking RhoC exon 2, exon 3, and the neomycin gene. (C) Southern blot analysis of tail DNA from $\mathrm{RhoC}^{+/+}, \mathrm{RhoC}^{+/-}$and $\mathrm{RhoC}^{-/-}$littermate mice hybridized to the $5^{\prime}$ probe in $A$. (D) Northern blot of total RNA from $\mathrm{RhoC}^{+/-}$or $R \mathrm{RhoC}^{-/-}$MEFs. The wild-type $(\mathrm{Wt}) \mathrm{RhoC}$ transcript $(1.4 \mathrm{~kb})$ appears in RNA derived from $R h o C^{+/-}$MEFs but not $R h o C^{-/-}$ MEFs.

B-cell activation in vitro in response to various stimuli was analyzed, but no differences in the proliferation of wild-type and $R h o C^{-/-}$cells were observed (Fig. 2B).

Rho GTPases have been reported to play a role in apoptosis (Embade et al. 2000; Liu et al. 2001). To investigate this hypothesis with respect to RhoC, wild-type and $\mathrm{RhoC}^{-1-}$ thymocytes and $\mathrm{T}$ cells were assayed for their apoptotic responses to dexamethasone, anti-CD95 antibody, and UV irradiation. No differences in apoptosis were observed between wild-type and mutant thymocytes (Fig. 2C; data not shown). It has also been suggested that Rho GTPases, particularly RhoA, control cell morphology and motility (Nobes and Hall 1995; Yoshioka et al. 1999; Nishimura et al. 2002). To determine the effect of RhoC deficiency on cell migration, motility assays were performed on various cell types from wild-type and $\mathrm{RhoC}^{-/-}$mice. However, loss of RhoC had no effect on the migration capacity of thymocytes, T cells, B cells, or neutrophils (Fig. 2D; data not shown). We conclude that $\mathrm{RhoC}$ is dispensable for T- and B-cell differentiation and activation, for T-cell and thymocyte apoptosis, and for the migration of hematopoietic cells.

We next examined the effect of RhoC deficiency on actin cytoskeleton reorganization in MEFs. Immunostaining for actin in wild-type and $R h o C^{-/-}$MEFs cultured in normal medium revealed no obvious difference in cytoskeletal structure (Fig. 3A,B). However, because Rho

GTPases are known to regulate stress fiber generation, we serum starved wild-type and $R h o C^{-/-}$MEFs for $48 \mathrm{~h}$ to induce stress fiber formation prior to actin immunostaining. Pronounced abnormalities in cytoskeletal structure were observed in $R h o C^{-/-}$MEFs compared with wild-type MEFs (Fig. 3C-F). In contrast to serum-starved wild-type MEFs, which retained their usual elongated shape and contained typical stress fibers, serum-starved $R h o C^{-/-}$MEFs assumed a round shape and showed a decreased of stress fibers.

Analyses of MEF apoptosis were also performed using death stimuli such as $\gamma$ and UV irradiation, but no differences were observed between wild-type and $\mathrm{RhoC}^{-/-}$ MEFs (data not shown).

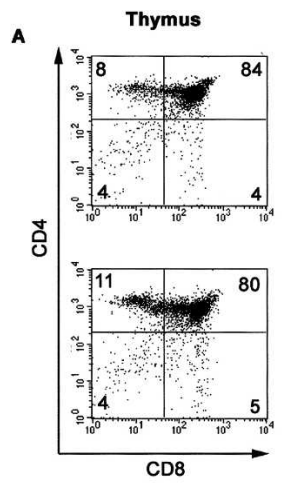

B
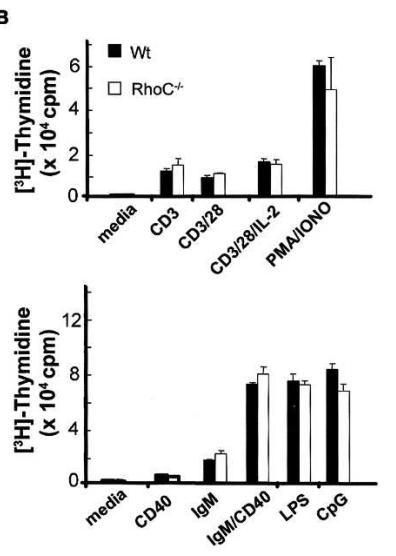

Lymph Node

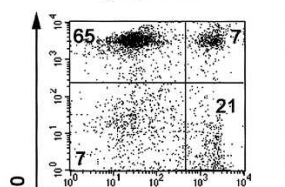

ลูญ

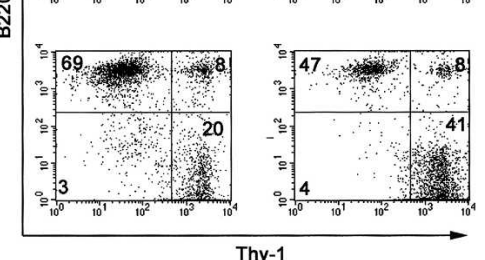

Thy-1

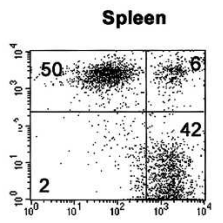

c
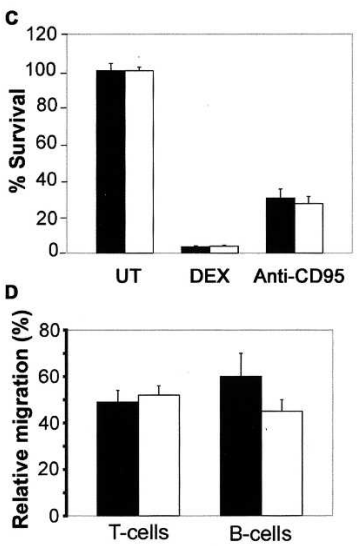

Figure 2. RhoC is not essential in T- or B-cell development, activation, apoptosis, or migration. $(A)$ Flow cytometric analyses of thymic, lymph node, and splenic total T- and B-lymphocyte populations in wild-type (upper panels) or $R_{h o C^{-/-}}$(lower panels) mice. Results representative of seven independent experiments are shown. (B) Proliferative responses of T and B lymphocytes to stimuli. Purified $\mathrm{T}$ and $\mathrm{B}$ cells from wild-type (Wt; black bars) and $R h o C^{-/-}$(white bars) mice were stimulated for $48 \mathrm{~h}$ with anti-CD3 with or without costimulation by anti-CD28 and/or IL-2, or PMA plus ionomycine (Iono) for T cells; or anti-IgM, anti-CD40, anti-IgM plus anti-CD40, LPS, or CpG for B cells. $\left[{ }^{3} \mathrm{H}\right]$-thymidine incorporation was then assessed. (C) Thymocyte sensitivity to apoptosis. Triplicate cultures of thymocytes from wild-type (black bars) or $R h o C^{-/-}$(white bars) mice were treated with dexamethasone (DEX) to induce mitochondria-mediated apoptosis, or with anti-CD95 to induce death-receptor-mediated apoptosis. Cell viability was determined $24 \mathrm{~h}$ later by Annexin V FITC/PI staining. (UT) Untreated control. (D) Cell migration. $\mathrm{T}$ and $\mathrm{B}$ cells and thymocytes $\left(\sim 10^{6}\right.$ cells) from wild-type (black bars) or $R h_{o} C^{-/-}$(white bars) mice were placed in the upper chamber of Transwell motility plates. Data shown are the mean percentages of duplicate sample of cells that migrated to the lower chamber after $24 \mathrm{~h}$. For $B, C$ and $D$, data are presented as the mean \pm SD and are representative of three independent experiments. 

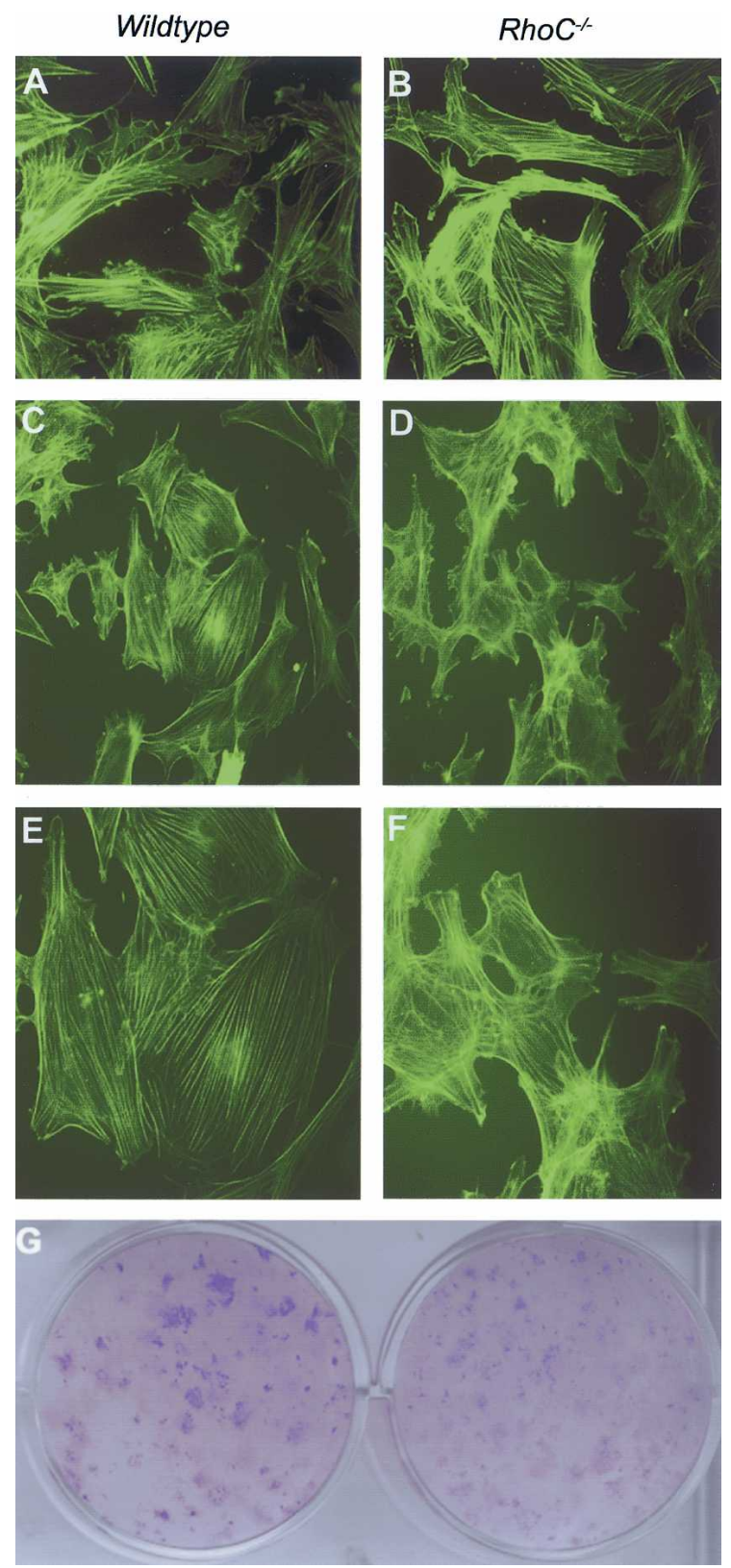

Figure 3. RhoC is required for stress fiber formation but not transformation. $(A, B)$ Normal culture conditions. Wild-type and $R h o C^{-/}$ MEFs were cultured in DMEM containing $10 \%$ FCS for $48 \mathrm{~h}$, fixed, and stained with FITC-phalloidin. Normal cytoskeletal structures can be seen even in the absence of RhoC. $(C, D)$ Stress conditions. Wild-type and $R h o C^{-/-}$MEFs were cultured in medium lacking FCS for $48 \mathrm{~h}$, fixed, and stained as in $A$ and $B$. Abnormal cytoskeletal structures are present in stressed $R h o C^{-/-}$MEFs. Magnification: $A-D, 20 \times .(E, F)$ Higher-magnification $(40 \times)$ view of the cells in $C$ and $D$. Rho $C^{-/-}$MEFs clearly show a defect in stress fiber formation. $(G)$ E1A/Ras transformation. Wild-type and $R h o C^{-/-}$MEFs were transformed with Ras/E1A retrovirus as described in Materials and Methods. No differences in the number of colonies and time of appearance of colonies were observed in the absence of RhoC. Data shown are representative of two independent experiments each.

Previous studies have shown that Ras GTPases require Rho GTPase function for oncogenic cell transformation (Olson et al. 1998). To investigate the specific role of RhoC in such transformation, wild-type and $\mathrm{RhoC}^{-/-}$
MEFs were transformed with E1A/Ras and c-myc/Ras oncogenes. $R \mathrm{R}_{\mathrm{oC}} \mathrm{C}^{-/} \mathrm{MEFs}$ were transformed to the same extent (same time of appearance, wild type: E1A/Ras $41 \pm 3$ colonies; c-myc/Ras $39 \pm 5$ colonies, $R h o C^{-/-}$: E1A/Ras $48 \pm 5$ colonies; c-myc/Ras $44 \pm 3$ colonies) as wild-type MEFs by these oncogenes (Fig. 3G), suggesting that RhoC is dispensable for E1A/Ras and c-myc/Rasmediated oncogenic transformation.

We next investigated whether RhoC was involved in tumor initiation, progression, or metastasis. For these studies, we used a model system consisting of Polyomavirus Middle T (PyV-mT) transgenic (Guy et al. 1992). All of these animals develop palpable mammary adenocarcinomas at $\sim 50 \mathrm{~d}$ of age, and show metastases in the lung at $\sim 70 \mathrm{~d}$ of age. We crossed $\mathrm{RhoC}^{+/+}$and $\mathrm{RhoC}^{-/-}$ littermates to PyV-mT mice and monitored the offspring for tumor development and metastasis. No differences were observed between $R h o C^{-/-} P y V-m T$ and $R h o C^{+/-}$ $P y V-m T$ mice with respect to frequency or size of tumors or time of first tumor appearance /wild type: number of tumors $=6-7$, size $=0.5-0.8 \mathrm{~cm}^{2}$, time of appearance $=55-60 \mathrm{~d} ; \quad R h o C^{-/-}:$number of tumors $=6-7$, size $=0.4-0.8 \mathrm{~cm}^{2}$, time of appearance $=55-60 \mathrm{~d}$; the number of tumors and their sizes were determined at the time of sacrifice). To examine the effect of RhoC deficiency on the histology of the primary tumors, $R h o C^{-/-}$ $P y V-m T$ and $R h o C^{+/}$PyV-mT mice were sacrificed between 110 and $140 \mathrm{~d}$ of age and their mammary tumors stained with H\&E. No significant differences in the structure of primary tumors were observed in the absence of RhoC (Fig. 4A,B). In addition, the proliferation of cancerous cells from primary tumors of $\mathrm{RhoC}^{-/-} \mathrm{PyV}$ $m T$ and $R h o C^{+/-} P y V-m T$ mice as well as the proliferation of metastactic nodules was equivalent, as indicated by comparable frequencies of Ki-67-positive cells and the intensity of Ki-67 staining in the primary tumors and metastases (Supplementary Fig. 1A).

Rho GTPases are known to be important for tumor angiogenesis and apoptosis. We therefore immunostained primary mammary tumors from $R_{h o C^{-/}} P y V-m T$ and $R h o C^{+/-} P y V-m T$ mice for expression of CD31 and Factor VIII, two markers of angiogenesis (Sapino et al. 2001). However, an absence of RhoC had no effect on levels of CD31 and Factor VIII expression in primary tumors (data not shown). The effect of RhoC deficiency on cell death in primary tumors was determined by TUNEL assay. Similar levels of TUNEL positive cells were observed in mammary tumors from $R_{h o C^{-/}} \mathrm{PyV}$ $m T$ and $R_{h o C}^{+/-} P y V-m T$ mice (Fig. 4E,F). Taken together, our results demonstrate that RhoC is dispensable for the in vivo initiation and progression of primary tumors. Furthermore, deficiency for RhoC affects neither tumor angiogenesis nor tumor cell proliferation or apoptosis.

We next addressed the role of RhoC in metastasis. While overexpression of RhoC has been correlated with metastasis, no direct evidence has been offered to support such a role in vivo. As noted above, $P y V-m T$ transgenic mice develop lung metastases by $70 \mathrm{~d}$ with $100 \%$ penetrance. We assessed the number of metastatic lesions in $\mathrm{H} \& \mathrm{E}$-stained sections of lungs from $\mathrm{RhoC}^{-/-}$ $P y V-m T$ and $R h o C^{+/-} P y V-m T$ mice of $110-140 \mathrm{~d}$ of age. While a large number of metastases $(37 \pm 12, n=12)$ were observed in the lungs of $R h o C^{+/-} P y V-m T$ mice, in the lungs of $R h o C^{-1-} P y V-m T$ mice a dramatically smaller number of metastases were present $(5 \pm 2$, 

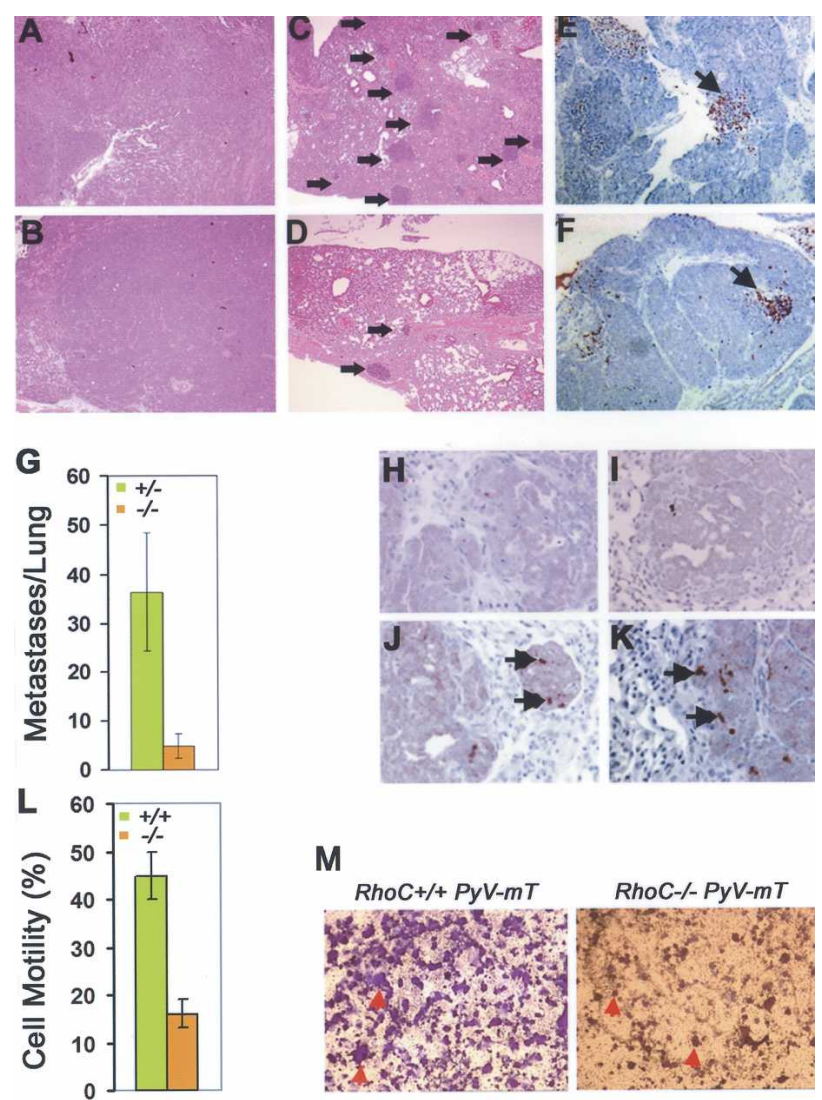

M

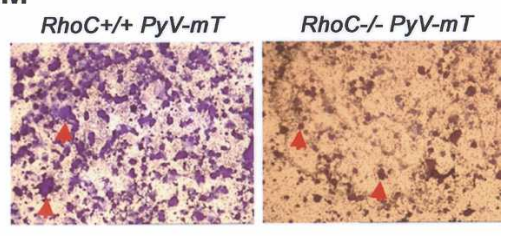

Figure 4. RhoC is essential for metastasis but not for primary tumor formation. $(A-F)$ Histological examination of H\&E-stained $R h o C^{+/+} P y V-m T(A, C)$ and $R h o C^{-/-} P y V-m T(B, D)$ tissue samples. $(A, B)$ Mammary adenocarcinoma. $(C, D)$ Lung metastases (arrows). $(E, F)$ TUNEL assays of sections of primary tumors from $R h o C^{++}$ $P y V-m T(E)$ and $R h o C^{-/-} P y V-m T(F)$ mice. Red arrows indicate TUNEL-positive cells. (G) Metastases in H\&E-stained lung sections from $R h o C^{+/+} P y V-m T(n=12)$ and $R h o C^{-/-} P y V-m T(n=16)$ mice. Metastases were counted on five lobes of the lung. Results shown are the mean number of metastases/lung $\pm \mathrm{SD}$. $(H-K)$ Lung sections from $R h o C^{+/+} P y V-m T(H, I)$ and $R h o C^{-/-} P y V-m T(J, K)$ mice were immunostained to detect cleaved caspase3. Arrows indicate cells positive for cleaved caspase3. $(L)$ In vitro migration efficiency. Cells from $R h o C^{+/+} P y V-m T$ (green) and $R h o C^{-/-} P y V-m T$ (orange) tumors were assayed for motility in Transwell assays as described in Materials and Methods. Data are expressed as the mean percentage (duplicate samples) of the initial seeded population that was able to migrate into the lower chamber. Five different tumors for each genotype were analyzed. $(M)$ In vitro invasiveness. Tumor cells from $\mathrm{RhoC}^{+/+} \mathrm{PyV}-\mathrm{mT}$ and $\mathrm{RhoC} \mathrm{C}^{-/-} \mathrm{PyV}-\mathrm{mT}$ mice were assessed for invasiveness using Transwell invasion chambers as described in Materials and Methods. Cells present in the polycarbonate membranes at $20 \mathrm{~h}$ post-seeding were stained with crystal violet. Representative results for $R h o C^{+/+} P y V-m T$ (left panel) and $R h o C^{-/-}$PyV-mT (right panel) tumors are shown.

$n=16)$ (Fig. 4C,D,G). We also compared the size of the metastases in control and mutant; at late stage (140 d), control lung metastases were bigger than those in the lungs of RhoC-deficient mice (wild type: $170 \pm 30 \mathrm{U}^{2}$;

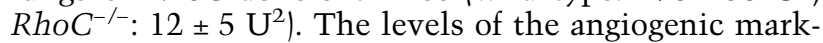
ers CD31 and Factor VIII were comparable in control and mutant lungs infiltrated with metastases.

To eliminate the possibility that macrophages had removed apoptotic cells in the late stages of death (those detected by TUNEL staining), we immunostained the lungs of $\mathrm{RhoC}^{+/-} \mathrm{PyV}-\mathrm{mT}$ and $\mathrm{RhoC}^{-/-} \mathrm{PyV}-\mathrm{mT}$ mice with antibody-recognizing cleaved caspase3 (which detects cells in the early stages of apoptosis.) An increased number of cells positive for cleaved caspase 3 were found in lung metastases from $R h o C^{-/} P y V-m T$ mice compared with the control (Fig. $4 \mathrm{H}-\mathrm{K}$ ) indicating that RhoCdeficient metastatic cells are more sensitive to apoptosis than their RhoC-competent counterparts. This observation may also help to explain why $R h o C^{-/-} P y V-m T$ metastases are smaller in size. To further investigate how RhoC deficiency affects metastases, we have performed assays to test the effect of loss of RhoC on motility and invasiveness using tumor cells from six $P y V-m T$ and five PyV-mT RhoC ${ }^{-/}$mice. Motility of the tumor cells was tested using the Transwell. The number of tumor cells able to migrate at different time points in this assay was consistently lower in $P y V-m T R h o C^{-/-}$compared with $P y V-m T$ genotype (Fig. 4L; data not shown). The invasiveness of these tumor cells was also tested using a Transwell invasion chamber. Tumor cells PyV-mT $R h o C^{-/-}$or $P y V-m T$ were seeded on the top chamber of the Transwell and $20 \mathrm{~h}$ later tumor cells present in the undersurfaces of the polycarbonate membranes were fixed, stained, and counted. The number of $P y V-m T$ $R h o C^{-/-}$tumor cells present in the matrigel was consistently lower compared with $P y V-m T$ tumor cells (Fig. 4M). These data support the idea that loss of RhoC in the tumors impairs their motility and invasiveness.

Our results demonstrate that the loss of RhoC decreased the in vivo metastatic potential of tumors cells, increased the in vivo apoptosis of metastatic cells, and reduced the motility and invasiveness of these cells in vitro. These finding lead us to speculate that there may be two components to the decreased metastasis in $R h o C^{-/-} P y V-m T$ mice. First, RhoC-deficient tumor cells likely migrate out of the primary tumor into secondary sites with reduced efficiency. Second, even if these mutant cells do seed in the lung, they are more sensitive to death induction.

RhoGTPases reportedly serve in many cellular processes, including embryogenesis, cellular migration, and tumorigenesis. Numerous hypotheses have been advanced to explain the functions of RhoGTPases in embryogenesis. However, our in vivo study shows that, like RhoB (Liu et al. 2001), RhoC is not essential for this process. Similarly, our data indicate that RhoC is not required for the migration of $\mathrm{T}$ cells, B cells, neutrophils, or MEFs. RhoC is also not essential for T- or B-cell development or function; for in vitro apoptosis or proliferation of thymocytes, T cells, B cells, or MEFs; or for the apoptosis or proliferation of primary tumor cells. In vitro oncogenic transformation can proceed in the absence of RhoC, and the incidence, size, and number of primary mammary tumors in vivo are not affected by RhoC deficiency. Rather, our data clearly demonstrate a specific role for RhoC in metastasis. In a mouse mammary adenocarcinoma model in which lung metastasis is essentially $100 \%$, almost no metastases were able to form in the lung in the absence of RhoC.

Our results may provide the biochemical justification for the observation of Suwa et al. (1998) that enhanced expression of RhoC correlates with the progression of pancreatic adenocarcinomas to a metastatic phenotype. Similarly, van Golen et al. (1999) have reported that RhoC protein is overexpressed in inflammatory breast cancers, the most lethal form of advanced breast cancer. We imagine a scenario in which initial overexpression of 
RhoA triggers formation of a primary tumor, but subsequent overexpression of RhoC leads to its metastasis. This hypothesis awaits further genetic investigation. In the meantime, an important finding of our study is that inactivation of RhoC does not affect embryogenesis, normal cell functions, or immune responses. Cancer therapies can thus be envisioned that block cancer cell metastasis by specifically inhibiting RhoC.

\section{Materials and methods}

Cells

E14K ES cells from 129/Ola mice were electroporated with the linearized targeting vector construct and cultured in the presence of $300 \mu \mathrm{g} / \mathrm{mL}$ of G418 for 11 d. G418-resistant ES cells were screened for homologous recombination by PCR. Correctly targeted ES clones were verified by Southern analysis using probes corresponding to the $5^{\prime}$ and $3^{\prime}$ RhoCflanking regions. ES clones were microinjected into C57BL/6 blastocysts to generate chimeric mice. MEFs derived from E13 embryos were prepared according to standard procedures. All cultures were maintained in DMEM and cells were plated at $1 \times 10^{5}$ in 24 -well plates.

\section{Mice}

PyV-mT transgenic mice were kindly provided by Dr. W. Muller (McGill University, Montreal, Canada). The heterozygous $R h o C$ mice were bred to $129 /$ Ola to perform the analysis with $P y V-m T$ mice, as well as to C57BL/6 mice to study T- and B-cell development. The mice were maintained in the animal facility of the Ontario Cancer Institute in accordance with the established ethical care regulations of Canadian Council in Animal Care (CCAC).

\section{RNA analysis}

Total RNA $(20 \mu \mathrm{g})$ from MEFs was analyzed by Northern blotting using standard procedures and a ${ }^{32} \mathrm{P}$-d-CTP-labeled full-length RhoC cDNA probe.

\section{Apoptosis assays}

Single-cell suspensions of thymocytes were prepared and washed twice in RPMI containing $10 \%$ fetal calf serum (FCS). Thymocytes were resuspended at $5 \times 10^{6}$ cells $/ \mathrm{mL}$ and plated in a final volume of $1 \mathrm{~mL}$ in 24 well flat bottom tissue culture plates. The following cell-death stimuli were administered: dexamethasone (Sigma) at 0.1 or $1 \mu \mathrm{M}$, anti-CD95 antibody (Pharmingen) at $1 \mu \mathrm{gg} / \mathrm{mL}$, and UV irradiation (DNA-Stratalinker) at 60 or $80 \mathrm{~mJ} / \mathrm{cm}^{2}$. Treated and untreated thymocytes were cultured for $24 \mathrm{~h}$ at $37^{\circ} \mathrm{C}$ in $5 \% \mathrm{CO}_{2}$, followed by harvesting and staining with AnnexinV FITC/propidium iodide (PI) kit (R\&D Systems) to detect cell death by flow cytometric analysis.

MEFs were also tested for cell death. At $12 \mathrm{~h}$ after the initial plating, the following cell death stimuli were administered: UV irradiation at 60 or $80 \mathrm{~mJ} / \mathrm{cm}^{2} ; \gamma$ irradiation at 800 or 1000 rads. Cells were harvested 48 or $72 \mathrm{~h}$ after the induction of cell death, stained with AnnexinV/PI kit (R\&D Systems), and analyzed by flow cytometry.

Detection of apoptosis in primary mammary tumors and lung metastases was performed by the TUNEL method using the In Situ Cell Death Detection kit (Boehringer Mannheim) according to the manufacturer's directions.

\section{Cell population assays}

$R h o C^{-/-}$and wild-type mice were sacrificed at 6-10 wk of age and thymi, spleens, lymph nodes, and bone marrow were harvested. Single-cell suspensions were prepared and stained with the following antibodies for cell surface analysis: anti-CD4, anti-CD8, anti-CD3, anti-CD95, anti-CD51, anti-CD25, anti-B220, anti-Thy1-1, anti-CD5, anti-CD69, anti-TCR, and anti-CD44 (ebioscience; Pharmingen). The stained cells were then analyzed by flow cytometry using the FACscan system and Cellquest software.

\section{T- and B-cell activation}

$\mathrm{T}$ and $\mathrm{B}$ cells were enriched from lymph nodes and spleens by fluorescence-activated cell sorting (FACS). All T- and B-cell experiments were performed using purified cells. For proliferation analysis, $10^{5}$ purified $\mathrm{T}$ or B cells were placed into round-bottom 96-well plates in RPMI-1640 medium containing $5 \%$ FCS. T cells were stimulated in triplicate with soluble anti-CD3 $(5 \mathrm{\mu g} / \mathrm{mL}$, Pharmingen) with or without anti-CD28 (2 $\mu \mathrm{g} / \mathrm{mL}$, Pharmingen), or IL-2 (100 U/mL, Pharmingen). B cells were stimulated in triplicate with IgM $(20 \mu \mathrm{g} / \mathrm{mL}$, Pharmingen $)$ with or without IL-4 $(5 \mathrm{ng} / \mathrm{mL})$, or CD40 $(1 \mathrm{\mu g} / \mathrm{mL}$, Pharmingen). B cells were also stimulated with either LPS $(10 \mu \mathrm{g} / \mathrm{mL}$; Sigma) or CpG $(0.2 \mu \mathrm{M})$. T and B cells were pulsed for the last $18 \mathrm{~h}$ with $1 \mu \mathrm{Ci}\left[{ }^{3} \mathrm{H}\right]$ thymidine (Amersham) per well and harvested at 24,48 , and $72 \mathrm{~h}$ after treatment.

\section{Immunohistochemistry}

MEFs were plated at $1 \times 10^{5}$ cells per well and cultured in DMEM with or without (for starvation) 10\% FCS for $48 \mathrm{~h}$. MEFs were washed in PBS followed by fixation in $4 \%$ paraformaldehyde in PBS for at least $10 \mathrm{~min}$ at room temperature. Fixed MEFs were permeabilized for $10 \mathrm{~min}$ with $0.1 \%$ ice-cold Triton X-100 in PBS and stained with $1.5 \mu \mathrm{g} / \mathrm{mL}$ of FITCphalloidin (Sigma).

\section{Transformation of MEFs}

Phoenix cells $\left(5 \times 10^{6}\right)$ were plated in a 10-cm dish, incubated for $24 \mathrm{~h}$, and then transfected by calcium-phosphate precipitation with $20 \mu \mathrm{g}$ of a retroviral plasmid $\left(15 \mathrm{~h}\right.$ at $\left.37^{\circ} \mathrm{C}\right)$. After $48 \mathrm{~h}$, the virus-containing medium was filtered (0.45- $\mu \mathrm{m}$ filter, Millipore) and supplemented with 4 $\mu \mathrm{g} / \mathrm{mL}$ polybrene (Sigma) (first supernatant). Viruses were allowed to accumulate in the medium for an additional $8 \mathrm{~h}$ and collected in the same way (second supernatant). Target fibroblasts were plated at $8 \times 10^{5}$ cells per 10-cm dish and incubated overnight. For infections, the culture medium was replaced by the appropriate first supernatant followed by centrifugation of the culture plates for $1 \mathrm{~h}$ and incubation for $8 \mathrm{~h}$ at $37^{\circ} \mathrm{C}$. The infection process was repeated using the second supernatant. Transformation of MEFs with E1A and Ras as well as Ras and c-myc was performed as described (Soengas et al. 1999). H-rasV12/c-myc or H-rasV12/ E1A was transduced into early passage MEFs derived from either wildtype or $\mathrm{RhoC}^{-/-}$mice.

\section{Histological analyses}

Mammary tumors and lungs were fixed in buffered formalin, processed for paraffin-embedded sectioning at $5 \mathrm{~mm}$ and stained with hematoxylin and eosin (H\&E) (Fisher). For immunohistochemistry, mammary tumors, and lung sections were incubated with anti-Ki-67 (Novocostra), antiCD31, anti-Factor 8 (Santa Cruz), or anti-caspase3 (Cell Signalling) antibodies.

\section{Migration and invasiveness assays}

Thymocytes or $\mathrm{T}$ or B cells $\left(5 \times 10^{5}\right)$ were seeded in the upper chamber of a Transwell motility plate (5 $\mu \mathrm{m}$, Costar). The lower chamber contained the cytokine SDF- $1(0.2 \mu \mathrm{g} / \mathrm{mL})$. After $24 \mathrm{~h}$ at $37^{\circ} \mathrm{C}$, the cells in the lower chamber were harvested and counted. The experiment was done in triplicate and repeated three times. For tumor cells, $10^{5}$ cells were seeded in the upper chamber of a Transwell motility plate $(8 \mu \mathrm{m}$, Costar) with lower chambers coated with collagen IV. The cells in the lower chamber were harvested and counted at $20 \mathrm{~h}$. Invasiveness assay was performed similarly with a Transwell invasion chamber (8 $\mu \mathrm{m}$, Becton Dickinson).

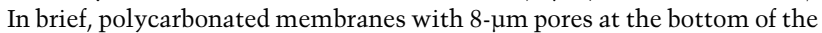
Transwells were already coated with a thin layer of matrigel, such that the cells were forced to degrade the matrigel barrier before they migrated to the undersurface of the polycarbonate membranes. The cells were fixed in ice-cold methanol and stained with crystal violet.

\section{Acknowledgments}

We thank Dick Hill, Anne Chambers, Razqallah Hakem, Benedicte Lemmers, and Jacinth Abraham for helpful discussions, and Mary Saunders for scientific editing. We thank William Muller (McGill) for providing us with the PyV-mT transgenic mouse and Scott Lowe (Cold Spring Harbor Laboratory) for providing us with E1A, Ras, and c-myc retroviruses. This work was supported by the Canadian Institute of Health Research (MOP \#57812) and by Amgen Inc.

\section{References}

Bishop, A.L. and Hall, A. 2000. Rho GTPases and their effector proteins. Biochem. J. 348 Pt 2: 241-255. 
Clark, E.A., Golub, T.R., Lander, E.S., and Hynes, R.O. 2000. Genomic analysis of metastasis reveals an essential role for RhoC. Nature 406: 532-535.

Corre, I., Gomez, M., Vielkind, S., and Cantrell, D.A. 2001. Analysis of thymocyte development reveals that the GTPase RhoA is a positive regulator of $\mathrm{T}$ cell receptor responses in vivo. J. Exp. Med. 194: $903-$ 914.

Embade, N., Valeron, P.F., Aznar, S., Lopez-Collazo, E., and Lacal, J.C. 2000. Apoptosis induced by Rac GTPase correlates with induction of FasL and ceramides production. Mol. Biol. Cell 11: 4347-4358.

Etienne-Manneville, S. and Hall, A. 2002. Rho GTPases in cell biology. Nature 420: 629-635.

Guy, C.T., Cardiff, R.D., and Muller, W.J. 1992. Induction of mammary tumors by expression of polyomavirus middle $\mathrm{T}$ oncogene: A transgenic mouse model for metastatic disease. Mol. Cell. Biol. 12: $954-$ 961.

Henning, S.W., Galandrini, R., Hall, A., and Cantrell, D.A. 1997. The GTPase Rho has a critical regulatory role in thymus development. EMBO J. 16: 2397-2407.

Liu, A.X., Rane, N., Liu, J.P., and Prendergast, G.C. 2001. RhoB is dispensable for mouse development, but it modifies susceptibility to tumor formation as well as cell adhesion and growth factor signaling in transformed cells. Mol. Cell. Biol. 21: 6906-6912.

Nishimura, Y., Itoh, K., Yoshioka, K., Ikeda, K., and Himeno, M. 2002. A role for small GTPase RhoA in regulating intracellular membrane traffic of lysosomes in invasive rat hepatoma cells. Histochem, J. 34: 189-213.

Nobes, C.D. and Hall, A. 1995. Rho, rac and cdc42 GTPases: Regulators of actin structures, cell adhesion and motility. Biochem. Soc. Trans. 23: $456-459$.

Olson, M.F., Paterson, H.F., and Marshall, C.J. 1998. Signals from Ras and Rho GTPases interact to regulate expression of p21Waf1/Cip1. $\mathrm{Na}$ ture 394: 295-299.

Raftopoulou, M. and Hall, A. 2004. Cell migration: Rho GTPases lead the way. Dev. Biol. 265: 23-32.

Sapino, A., Bongiovanni, M., Cassoni, P., Righi, L., Arisio, R., Deaglio, S., and Malavasi, F. 2001. Expression of CD31 by cells of extensive ductal in situ and invasive carcinomas of the breast. [See comment.] J. Pathol. 194: 254-261.

Schmidt, A. and Hall, A. 2002. Guanine nucleotide exchange factors for Rho GTPases: Turning on the switch. Genes \& Dev. 16: 1587-1609.

Soengas, M.S., Alarcon, R.M., Yoshida, H., Giaccia, A.J., Hakem, R., Mak, T.W., and Lowe, S.W. 1999. Apaf-1 and caspase-9 in p53-dependent apoptosis and tumor inhibition. Science 284: 156-159.

Suwa, H., Ohshio, G., Imamura, T., Watanabe, G., Arii, S., Imamura, M., Narumiya, S., Hiai, H., and Fukumoto, M. 1998. Overexpression of the rhoC gene correlates with progression of ductal adenocarcinoma of the pancreas. Br. J. Cancer 77: 147-152.

van Golen, K.L., Davies, S., Wu, Z.F., Wang, Y., Bucana, C.D., Root, H., Chandrasekharappa, S., Strawderman, M., Ethier, S.P., and Merajver, S.D. 1999. A novel putative low-affinity insulin-like growth factorbinding protein, LIBC (lost in inflammatory breast cancer), and RhoC GTPase correlate with the inflammatory breast cancer phenotype. Clin. Cancer Res. 5: 2511-2519.

van Golen, K.L., Wu, Z.F., Qiao, X.T., Bao, L., and Merajver, S.D. 2000 RhoC GTPase overexpression modulates induction of angiogenic factors in breast cells. Neoplasia 2: 418-425.

Weber, J.D., Hu, W., Jefcoat Jr., S.C., Raben, D.M., and Baldassare, J.J. 1997. Ras-stimulated extracellular signal-related kinase 1 and RhoA activities coordinate platelet-derived growth factor-induced G1 progression through the independent regulation of cyclin D1 and p27. J. Biol. Chem. 272: 32966-32971.

Yoshioka, K., Nakamori, S., and Itoh, K. 1999. Overexpression of small GTP-binding protein RhoA promotes invasion of tumor cells. Cancer Res. 59: 2004-2010. 


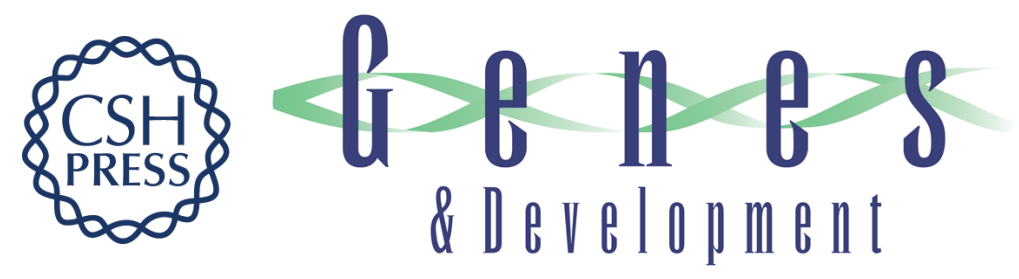

\section{RhoC is dispensable for embryogenesis and tumor initiation but essential for metastasis}

Anne Hakem, Otto Sanchez-Sweatman, Annick You-Ten, et al.

Genes Dev. 2005, 19:

Access the most recent version at doi:10.1101/gad.1310805

\section{Supplemental http://genesdev.cshlp.org/content/suppl/2005/08/18/gad.1310805.DC1 Material}

References This article cites 19 articles, 11 of which can be accessed free at: http://genesdev.cshlp.org/content/19/17/1974.full.html\#ref-list-1

\section{License}

Email Alerting

Receive free email alerts when new articles cite this article - sign up in the box at the top Service 